\title{
Article \\ Microstructural and Mechanical Properties Characterization of Graphene Oxide-Reinforced Ti-Matrix Composites
}

\author{
Zhaomei Wan, Jiuxiao Li *, Dongye Yang and Shuluo Hou
}

check for

updates

Citation: Wan, Z.; Li, J.; Yang, D.; Hou, S. Microstructural and Mechanical Properties Characterization of Graphene

Oxide-Reinforced Ti-Matrix

Composites. Coatings 2022, 12, 120.

https://doi.org/10.3390/

coatings 12020120

Academic Editor: Anton Ficai

Received: 6 December 2021

Accepted: 16 January 2022

Published: 21 January 2022

Publisher's Note: MDPI stays neutral with regard to jurisdictional claims in published maps and institutional affiliations.

Copyright: (C) 2022 by the authors. Licensee MDPI, Basel, Switzerland. This article is an open access article distributed under the terms and conditions of the Creative Commons Attribution (CC BY) license (https:// creativecommons.org/licenses/by/ $4.0 /)$.
School of Materials Engineering, Shanghai University of Engineering Science, Shanghai 201620, China; wanzhaomei123@163.com (Z.W.); ydy_hit@163.com (D.Y.); hsl111hsl@163.com (S.H.)

* Correspondence: lijiuxiao@126.com
Abstract: The 0.1-0.7 wt.\% graphene oxide (GO)-reinforced Ti-matrix composites (TMCs) were prepared by the hot-pressed sintering method. The effects of GO content on the mechanical properties of TMCs were investigated. The microstructure of TMCs was analyzed. The results show that the microstructure of $\mathrm{Ti}$ and TMCs is equiaxed $\alpha$. The average grain size of TMCs decreases with GO increasing. GO can react with Ti to form TiC at high temperatures. Meanwhile, GO is also presented in the matrix. The hardness of TMCs is higher than that of pure Ti. The maximum hardness is $320 \mathrm{HV}$, which is $43 \%$ higher than that of pure Ti. The yield strength of Ti- $0.5 \mathrm{wt} . \%$ GO sintered at $1373 \mathrm{~K}$ is $1324 \mathrm{MPa}, 77 \%$ more than pure Ti. The strengthening mechanism of TMCs is the fine-grained strengthening and the reinforcement that bear the stress from the matrix. The friction coefficient of Ti- 0.3 wt. $\%$ GO sintered at $1373 \mathrm{~K}$ comes up to 0.50 , which is reduced by 0.2 compared with pure Ti.

Keywords: Ti-matrix composites (TMCs); graphene oxide (GO); mechanical properties; reinforcement

\section{Introduction}

$\mathrm{Ti}$ and Ti alloys, with their excellent mechanical properties, corrosion resistance and relatively low density, are essential materials for structural applications in aerospace, defense, automotive, etc. [1-5]. In the past, a large amount of research has been carried out to improve the properties of $\mathrm{Ti}$ alloys by adding reinforcing phases, such as graphite, carbon nanotubes, $\mathrm{TiC}$ and $\mathrm{TiB}$, etc. [6-10].

Compared with the common materials, graphene has excellent mechanical properties, thermal and electrical conductivity [11-14]. As a reinforcing phase, graphene was widely used to improve the properties of metal-matrix composites [15-19]. Shin et al. [20] reported that few-layer graphene-reinforced Al-matrix composites by powder metallurgic method. The compressive strength of Al-matrix composites with 0.7 vol. $\%$ graphene was twice that of pure Al. Chen et al. [21] Added different graphene contents into the $\mathrm{Cu}$ matrix, the results showed that the yield strength of $\mathrm{Cu}$-matrix composites with 0.6 vol.\% graphene was about twice as pure $\mathrm{Cu}$, and the friction coefficient of the composite was about 0.25 , which was about $40 \%$ of that of pure $\mathrm{Cu}$. There are hydroxyl, carboxyl and oxidizing functional groups on the surface of graphene oxide (GO), which can improve the dispersion of GO in the matrix [22]. Shuai et al. [23] prepared GO-reinforced magnesium alloy by laser melting method, and the research results showed that the compression yield strength of the magnesium alloy with 1wt.\% graphene was increased by 30\%. Mu et al. [24] prepared graphene nanosheets discontinuous reinforced Ti-matrix composites (TMCs) by powder metallurgy. The test results showed that the ultimate strength of TMCs containing $0.1 \mathrm{wt} . \%$ graphene nanoplates (GNPS) was 54.2\% higher than that of the Ti matrix. Cao et al. [25] synthesized GNPs-reinforced TMCs with 1.2 vol.\% GNPs. Compared with the monolithic titanium alloy, the composite with 1.2 vol.\% GNPs exhibits significantly improved elastic modulus and strength. The sliding wear test shows that the wear volume loss of composite with 1.2 vol.\% GNPs decreased by $18 \%$ than pure Ti. Dong et al. [26] fabricated oxide nanosheets (GONs)-reinforced TMCs composites. It was revealed that yield strength and 
ultimate tensile strength of TMCs with the $0.6 \mathrm{wt} \%$ GONs were increased by $7.44 \%$ and $9.65 \%$ as compared to those of pure Ti. Cao et al. [27] reported the tensile strength at room temperature after R\&A can reach $1206 \mathrm{MPa}$ for 0.3 wt.\% GNP-reinforced TMCs, which increased by $46 \%$ compared with pure Ti.

These reported TMCs demonstrated that the interface between graphene and Ti matrix owns effective load-transfer ability due to the strong $\mathrm{Ti}-\mathrm{C}$ ionic bond and $\mathrm{TiC}$ reaction products effect to enhance mechanical properties. However, graphene is not easy to be uniformly dispersed in matrix attributed to graphemic nano-characters and strong Vander Waals forces between graphene, limiting the improvement of mechanical properties. In this paper, powder metallurgy (PM) is a favorable method in MMCs due to its low cost, flexibility, and ease of control. Irregular Ti powder has a much higher apparent volume than spherical powders, which is beneficial for the uniform distribution of GO. GO at a low content level usually exhibit excellent strengthening effect in TMCs, which can be attributed to its various oxygen functional groups (hydroxyl, carboxyl acid, and epoxy) on the surface and sheet edges, improving dispersibility in solvents. The interface wettability between in-situ TiC and titanium matrix is excellent, which can significantly improve the interface bonding and matching, and improve the interface strength. In this work, GO-reinforced TMCs were prepared and microstructures were observed. In addition, the mechanical properties and strengthening mechanisms of GO-reinforced TMCs are discussed.

\section{Experimental Procedure}

The particle size of pure Ti powder is about $150 \mathrm{um}$. The dispersion of GO was mixed with pure Ti by ultrasonic stirring method and then GO-reinforced TMCs were sintered in a vacuum hot-pressed sintering furnace. The mass percentages of GO are $0.1 \mathrm{wt} \%$, $0.3 \mathrm{wt} . \%, 0.5 \mathrm{wt} . \%$ and $0.7 \mathrm{wt} . \%$ respectively. The sample was sintered for $1 \mathrm{~h}(1273 \mathrm{~K}$, $1373 \mathrm{~K}$, pressure of $30 \mathrm{MPa}$, vacuum of $1 \times 10^{-3} \mathrm{~Pa}$ ) in a vacuum hot-pressed sintering furnace. The details of TMCs reinforced with $0-0.7$ wt.\% GO are shown in Table 1.

Table 1. Materials of different GO content at different sintering temperatures.

\begin{tabular}{ccc}
\hline Materials & GO Content (wt. $\%)$ & Sintering Temperature (K) \\
\hline Ti1 & 0 & 1273 \\
TMC1 & 0.1 & 1273 \\
TMC2 & 0.3 & 1273 \\
TMC3 & 0.5 & 1273 \\
TMC4 & 0.7 & 1273 \\
Ti2 & 0 & 1373 \\
TMC5 & 0.1 & 1373 \\
TMC6 & 0.3 & 1373 \\
TMC7 & 0.5 & 1373 \\
TMC8 & 0.7 & 1373 \\
\hline
\end{tabular}

The microstructure was analyzed by optical microscope (OM, Olympus-BX53, Olympus, Tokyo, Japan) and scanning electron microscope (SEM, NOVA, NanoSEM 230, FEI, Hillsboro, OR, USA). The phase analysis of the sample was carried out by X-ray diffraction (XRD, D-max 2550 V, Japan Science Corporation, Tokyo, Japan) with a Cu-K $\alpha$ radiation source $\left(5-100^{\circ}, 5^{\circ} / \mathrm{min}\right)$. The accelerating voltage and tube current are $30 \mathrm{KV}$ and $25 \mathrm{~mA}$. The average grain size was measured by the average interception method. The hardness of the sample was measured by hardness tester (MH-VK, Shanghai Taiming Optical Instrument Co., Ltd., Shanghai, China) at $200 \mathrm{~N}$ for $15 \mathrm{~s}$. Nine different points were taken for each sample to be averaged. Room compression test was conducted on Zwick-Z020 (Zwick, Ulm, Germany). The compression rate is $0.6 \mathrm{~mm} / \mathrm{min}$. The size of compression samples is $\varnothing 4 \mathrm{~mm} \times 6 \mathrm{~mm}$. A tribological test was conducted on a friction and wear testing machine (HT-1000, Zhongke Kaihua Technology Development Co., Ltd., Lanzhou, China). The method of dry friction of the ball plate was adopted. GCr15 ball with a diameter of $6 \mathrm{~mm}$ was used as friction pair. The sliding time was $1200 \mathrm{~s}$ under a regular load of 3 N. Friction 
and wear experiments were repeated three times to take the average value. The wear width, depth and volume were measured by surface profiler (MT-500, producerZhongke Kaihua Technology Development Co., Ltd., Lanzhou, China).

\section{Result Discussion}

\subsection{Phase Analysis}

Figure 1 shows the XRD pattern of TMCs. Figure 1a,b show samples sintered at $1273 \mathrm{~K}$ and $1373 \mathrm{~K}$. The peak of $\alpha$-Ti is detected by XRD. The $\mathrm{C}$ peak is at $26.5^{\circ}(002)$. Figure $1 \mathrm{c}$ is the locally enlarged view of $25-28^{\circ}$ in Figure $1 \mathrm{~b}$. The peak of TiC appeared at 41.08 (200). Figure $1 \mathrm{~d}$ is the locally enlarged view of $40.4-42^{\circ}$ in Figure $1 \mathrm{~b}$. The peak of $\mathrm{TiO}$ is at $29.4^{\circ}$ (101) and $30.8^{\circ}$ (103). It is evident that the intensity of TiC increases with the increase of the GO content. The result indicates that $\mathrm{GO}$ reacts with $\mathrm{Ti}$ at high temperatures. The Gibbs free energy of $\mathrm{TiC}$ from the reaction of $\mathrm{GO}$ with $\mathrm{Ti}$ can be calculated by the following formula [28].

$$
\mathrm{Ti}+\mathrm{C}=\mathrm{TiC}
$$

$$
\begin{gathered}
\Delta \mathrm{G}=-184571.8+41.382 \mathrm{t}-5.042 \mathrm{Tln} t+2.425 \times 10-3 \mathrm{~T} 2-9.79 \times 105 / \mathrm{T} \\
(\mathrm{T}<1939 \mathrm{~K}) .
\end{gathered}
$$
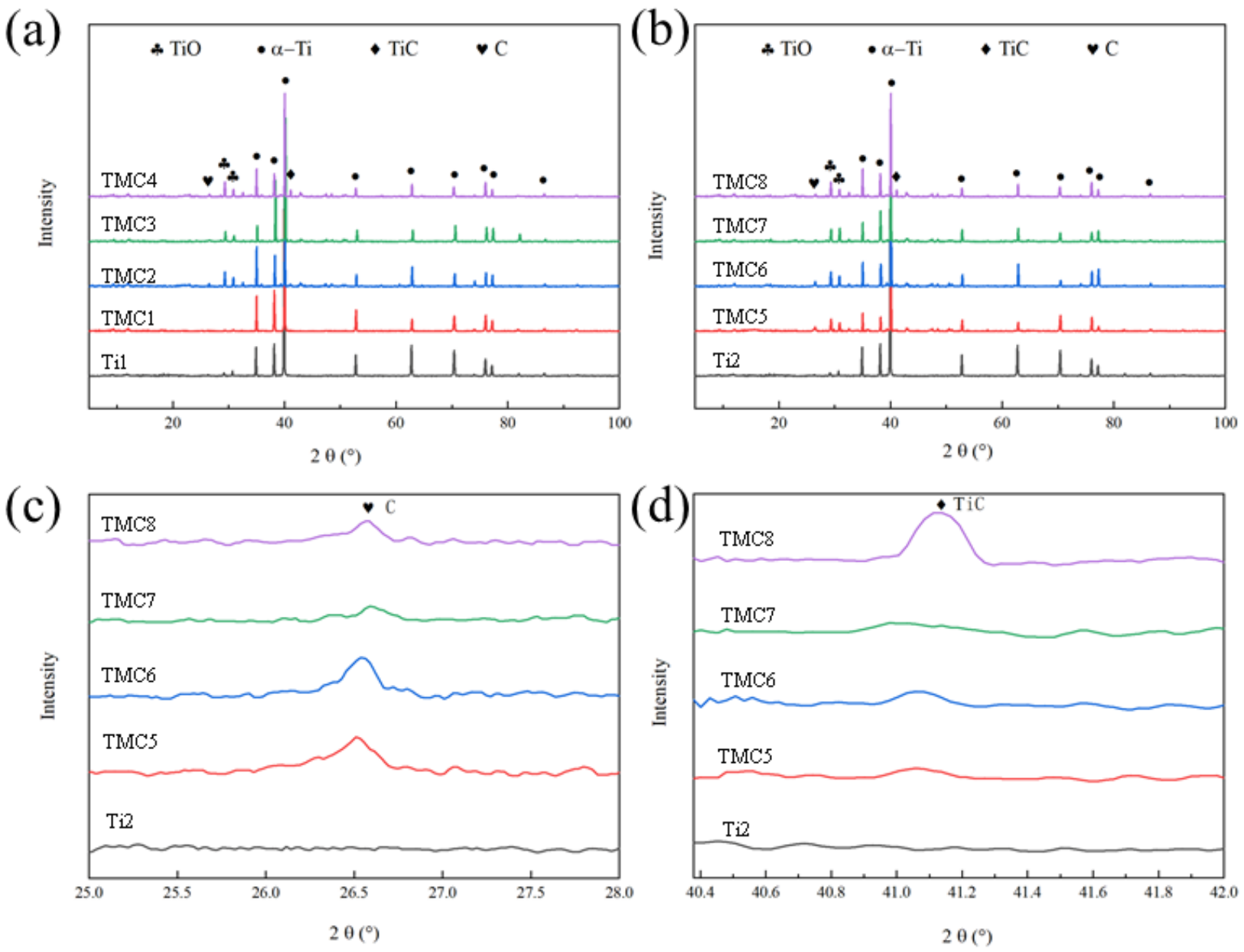

Figure 1. X-ray diffraction of Ti and TMCs sintered at: (a) $1273 \mathrm{~K}$; (b) $1373 \mathrm{~K}$; (c) 25-28 in (b); (d) $40.4-42.0^{\circ}$ in $(\mathbf{b})$.

The calculated Gibbs free energy of TMCs sintered at $1273 \mathrm{~K}$ and $1373 \mathrm{~K}$ are about $-157.75 \mathrm{~kJ} / \mathrm{mol}$ and $-174 \mathrm{~kJ} / \mathrm{mol}$. It shows that the hard second phase TiC can be formed spontaneously via a reaction between GO and Ti during hot-pressed sintering. 


\subsection{Microstructure}

The SEM micrographs of TMCs are outlined in Figure 2. The grain boundary is relatively apparent. The microstructure of Ti and TMCs is equiaxed $\alpha$. There are no welldefined pores in the material. With the increase of GO content, the GO aggregation can be displayed in Figure 2e,i,j. With the increase of sintering temperature, Ti atoms in the composites can migrate effectively, thus achieving better densification. The average grain size of TMCs decreases with GO increasing. The average grain sizes of Ti and TMCs are listed in Table 2. The average grain size of TMC 8 is about $38.3 \mu \mathrm{m}$, which decreases by $52 \%$ compared with that of Ti2. In the process of grain growth, GO and TiC can hinder the movement of the grain boundary, and the grain growth is restricted. So, the grain size of TMCS is smaller than pure Ti.
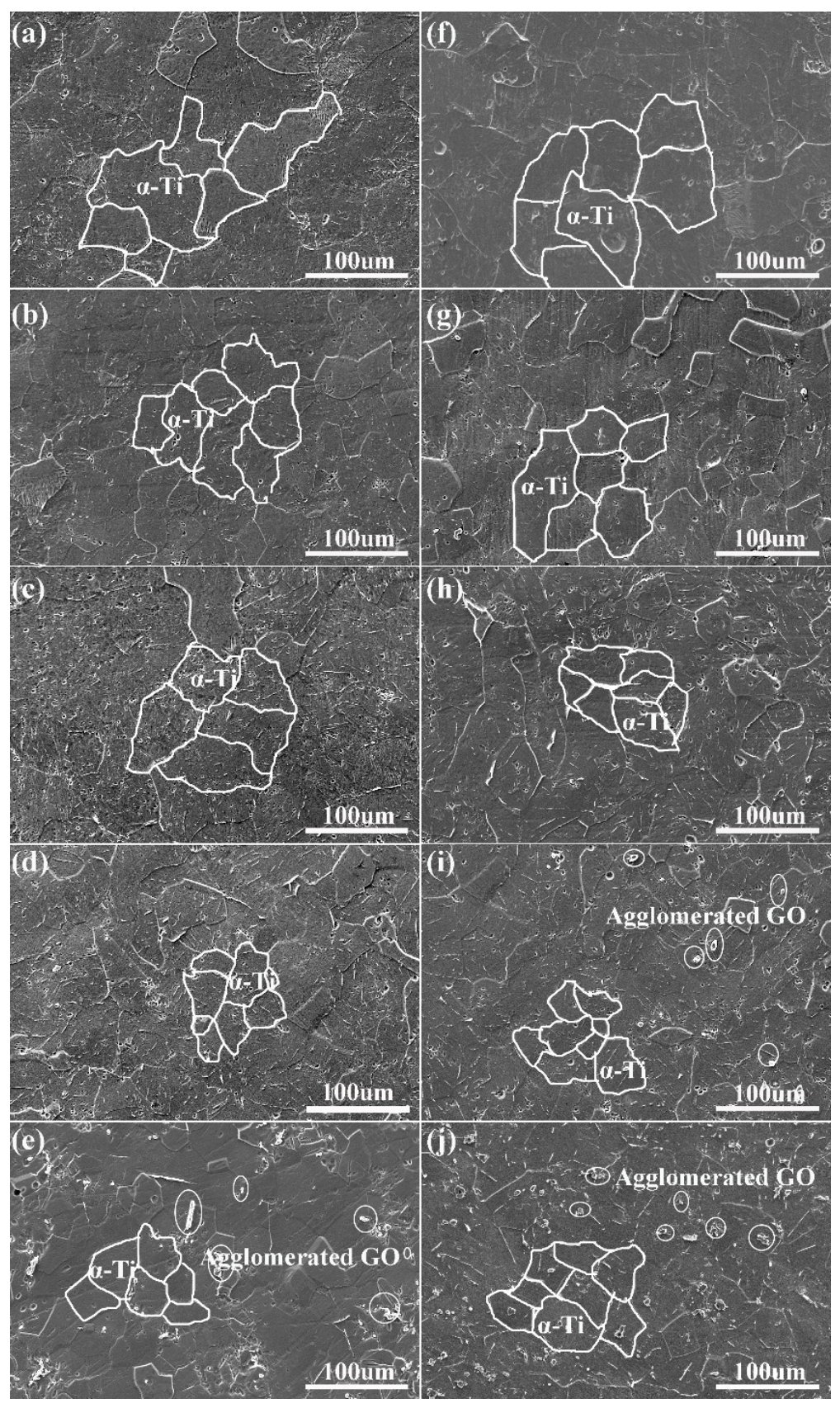

Figure 2. The SEM diagram of TMCs. (a) Ti1; (b) TMC1; (c) TMC2; (d) TMC3; (e) TMC4; (f) Ti2; (g) TMC5; (h) TMC6; (i) TMC7; (j) TMC8. 
Table 2. Average grain Size of Ti and TMCs.

\begin{tabular}{cccc}
\hline Materials & Average Grain Size $(\boldsymbol{\mu m})$ & Materials & Average Grain Size $(\boldsymbol{\mu m})$ \\
\hline Ti1 & $78.5 \pm 0.4$ & Ti2 & $80.3 \pm 0.6$ \\
TMC1 & $70.6 \pm 0.8$ & TMC5 & $76.5 \pm 0.8$ \\
TMC2 & $57.2 \pm 0.7$ & TMC6 & $63.4 \pm 0.7$ \\
TMC3 & $43.5 \pm 0.9$ & TMC7 & $50.6 \pm 0.8$ \\
TMC4 & $36.7 \pm 0.6$ & TMC8 & $38.3 \pm 0.5$ \\
\hline
\end{tabular}

The EDS of TMC8 is shown in Figure 3. Location 1 is the enrichment area of $\mathrm{O}$ and C, and location 2 is the enrichment area of $\mathrm{C}$. Ti is less at 1 and 2 locations. Figure 4 is the EDS of TMC8, which contains both strip-like second phase and granular matter. Figure $4 \mathrm{a}$ is the line scanning of striped second phase matter. The content of $\mathrm{C}$ and $\mathrm{O}$ is higher than that in other areas, and the content of $\mathrm{Ti}$ is lower than that in other areas. According to the XRD analysis results, it is inferred that it was undamaged flake-like GO. The result is consistent with Dong's work [29]. Figure $4 \mathrm{~b}$ is the analysis results of granular matter. The C appears, and the content of $\mathrm{Ti}$ is reduced compared with other areas. Combined with the analysis of $\mathrm{XRD}$ results, it is judged that this is $\mathrm{TiC}$ generated by the reaction of $\mathrm{GO}$ and Ti. Similar results have been reported [30,31].
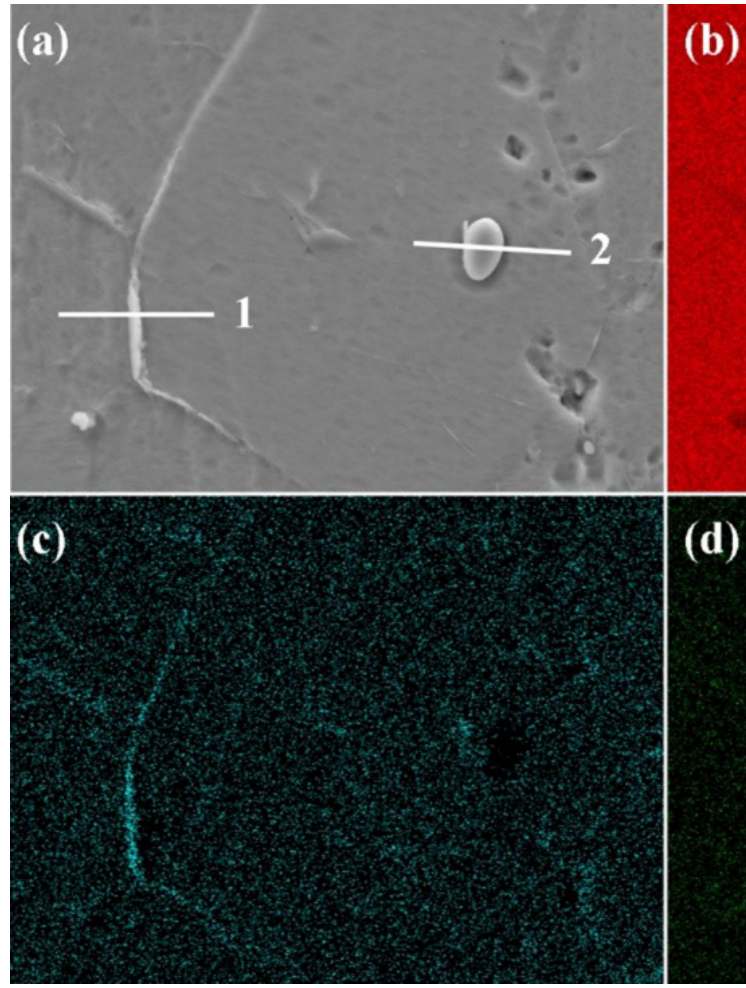

Figure 3. EDS of TMC8. (a) Surface scanning of TMC8; (b) Ti distribution in (a); (c) O distribution in (a); (d) C distribution in (a). 

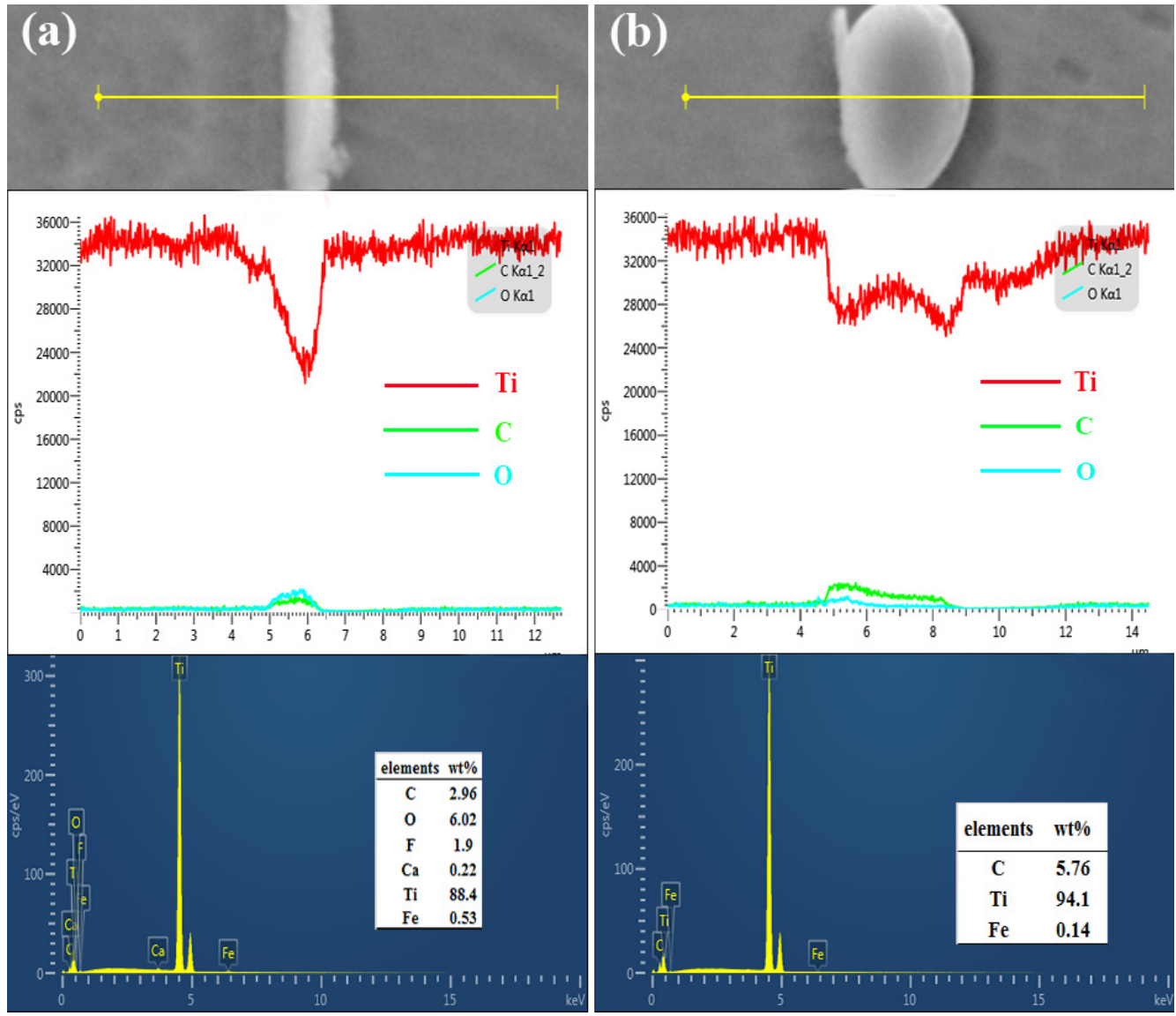

Figure 4. EDS of TMC8. (a) Line scanning surface of striped second-phase matter; (b) line scanning surface of granular matter.

\subsection{Properties Analysis}

\subsubsection{Hardness}

The hardness of Ti and TMCs is shown in Figure 5 and Table 3. The hardness of the TMCs becomes higher and higher with the increase of GO content. The hardness of TMC4 and TMC 8 are $300 \mathrm{HV}$ and $320 \mathrm{HV}$, which is separately increased by $42 \%$ and $43 \%$ compared with that of pure Ti. As is mentioned above, GO reacts with pure Ti to form $\mathrm{TiC}$ at high temperature. The hard second phase $\mathrm{TiC}$ can resist local plastic deformation of TMCs and improve the hardness of TMCs. The higher the temperature, the greater the activation energy and the more $\mathrm{TiC}$, which raises the hardness of TMCs sintered at $1373 \mathrm{~K}$.

Table 3. Hardness of Ti and TMCs.

\begin{tabular}{cccc}
\hline Materials & Hardness/HV & Materials & Hardness/HV \\
\hline Ti1 & $210 \pm 3$ & Ti2 & $223 \pm 5$ \\
TMC1 & $239 \pm 6$ & TMC5 & $241 \pm 6$ \\
TMC2 & $245 \pm 4$ & TMC6 & $250 \pm 4$ \\
TMC3 & $268 \pm 2$ & TMC7 & $280 \pm 3$ \\
TMC4 & $300 \pm 5$ & TMC8 & $320 \pm 4$ \\
\hline
\end{tabular}




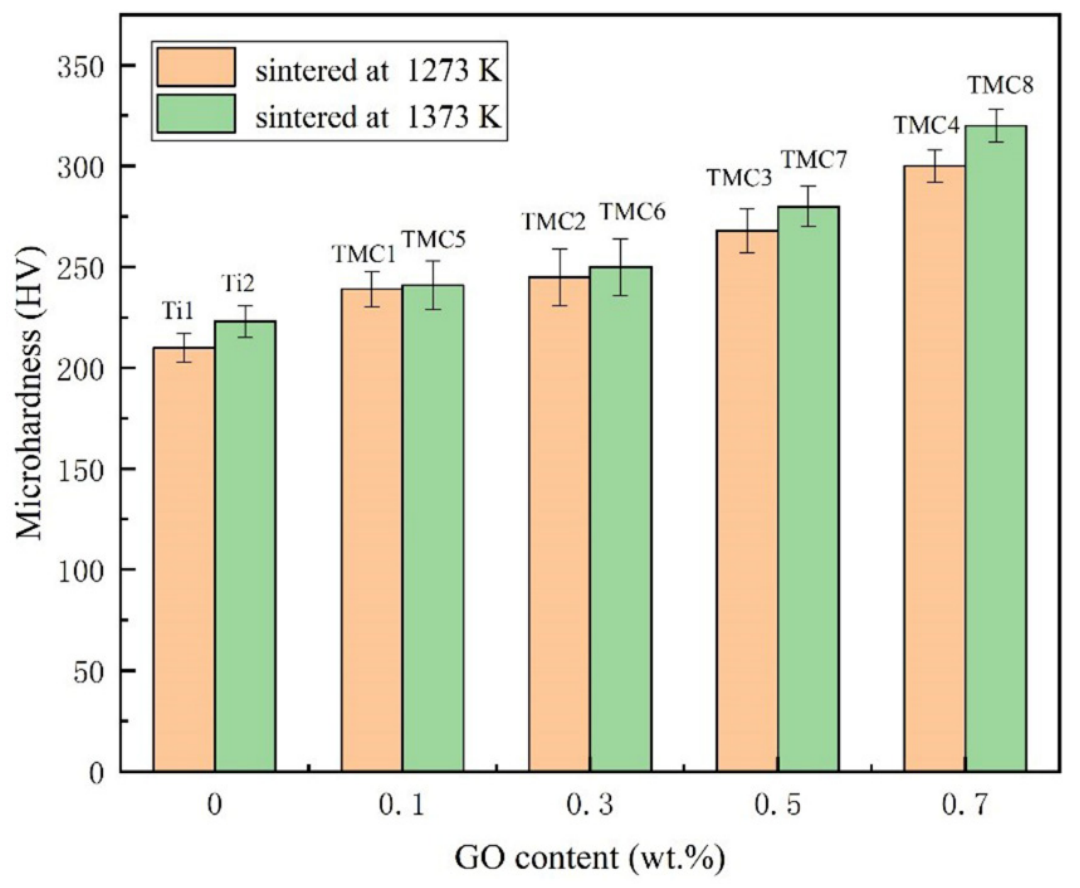

Figure 5. Hardness of Ti and TMCs.

\subsubsection{Compression Properties}

Figure $6 \mathrm{a}, \mathrm{b}$ show the compressive stress-strain curves of Ti and TMCs sintered at $1273 \mathrm{~K}$ and $1373 \mathrm{~K}$. The detail data are listed in Table 4 . The yield strength of TMC4 is $1024 \mathrm{MPa}$, which is increased by $42 \%$ compared with that of Ti1. The yield strength of TMC7 is $1324 \mathrm{MPa}$, which is increased by 77\% compared with that of Ti2. The yield strength detail of Ti and TMCs is listed in Table 3. The yield strength increases with the increase of GO content sintered at $1273 \mathrm{~K}$. But, the yield strength of TMC 8 is lower than TMC7. This is due to the agglomeration of GO. Similar results have been reported by Liu [32].

(a)

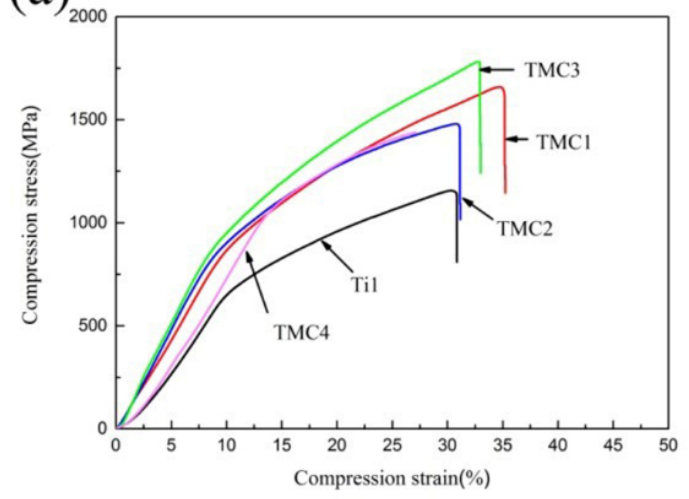

(b)

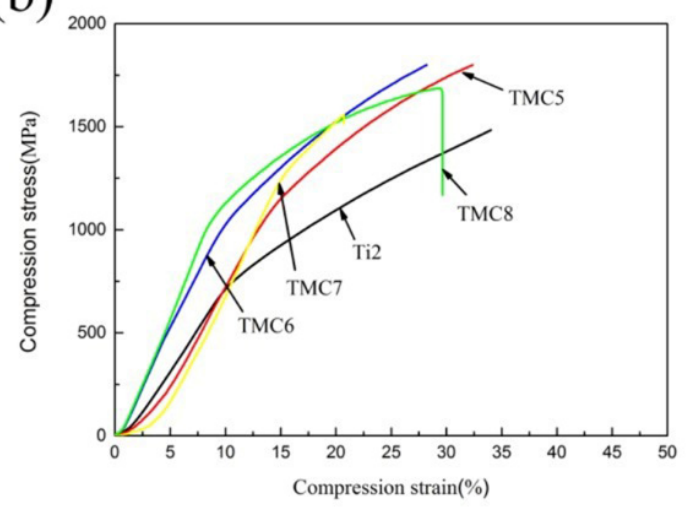

Figure 6. Stress-strain curve of Ti and TMCs sintered at (a) $1273 \mathrm{~K}$ and (b) $1373 \mathrm{~K}$.

Table 4. Compressive properties of Ti and TMCs.

\begin{tabular}{cccc}
\hline Materials & Yield Strength/MPa & Materials & Yield Strength/MPa \\
\hline Ti1 & $721 \pm 3$ & Ti2 & $748 \pm 5$ \\
TMC1 & $859 \pm 5$ & TMC5 & $1025 \pm 7$ \\
TMC2 & $906 \pm 6$ & TMC6 & $1135 \pm 8$ \\
TMC3 & $977 \pm 4$ & TMC7 & $1324 \pm 6$ \\
TMC4 & $1024 \pm 7$ & TMC8 & $1146 \pm 9$ \\
\hline
\end{tabular}


Figure 7 shows the OM diagram near the compression fracture of TMC7. Elongated $\alpha$-Ti grains and fractured reinforcement are observed in Figure 7. It can be inferred that the reinforcement bears the load during the compression process, thereby improving the strength of the TMCs.

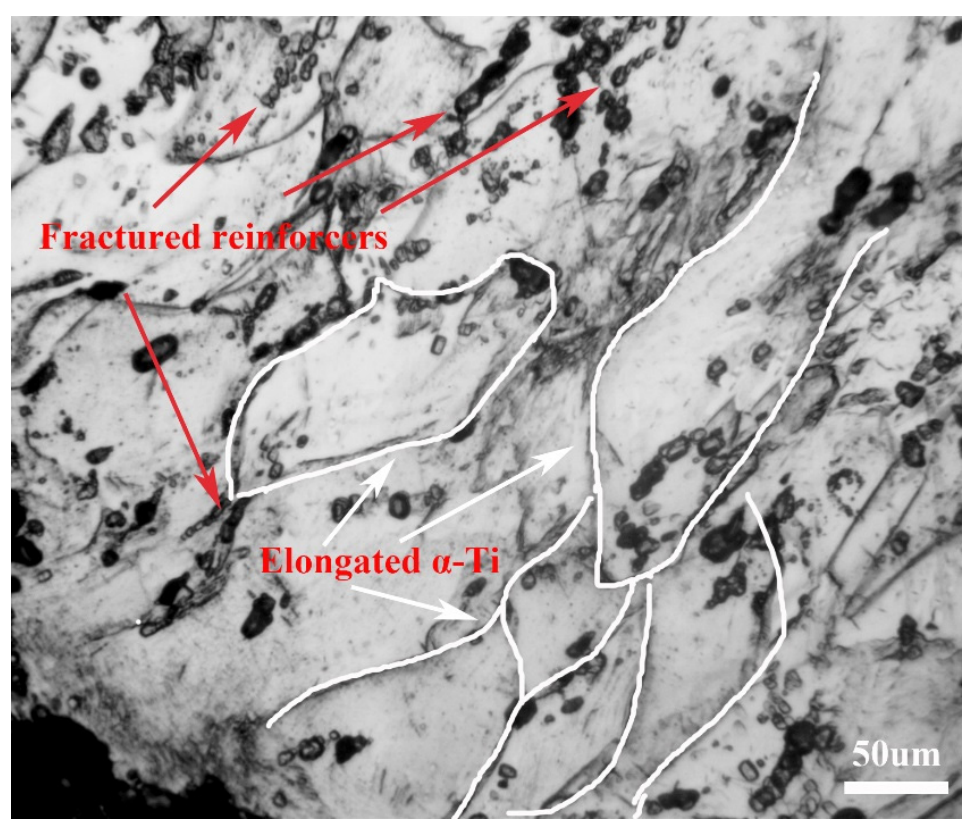

Figure 7. OM diagram near the compression fracture of TMC7.

There are two reasons for strengthening TMCs.

1. The reinforcement $\mathrm{GO}$ and $\mathrm{TiC}$ bear part of the load during the deformation process. The shear hysteresis model is usually used to evaluate the strength of TMCs. The yield strength $\left(\sigma_{\mathrm{c}}\right)$ can be expressed as $[20,33]$

$$
\sigma_{\mathrm{c}}=\sigma_{\mathrm{r}} \mathrm{V}_{\mathrm{r}}\left(1-\frac{l_{\mathrm{c}}}{2 \mathrm{l}}\right)+\sigma_{\mathrm{m}}\left(1-\mathrm{V}_{\mathrm{r}}\right)
$$

$\sigma_{\mathrm{m}}$ is the yield strength of Ti matrix, $\sigma_{\mathrm{r}}$ is the fracture strength of reinforcement, $\mathrm{V}_{\mathrm{r}}$ is the volume fraction of reinforcement, 1 is the length of reinforcement, and $l_{c}$ is the critical length of the reinforcement.

$$
1_{\mathrm{c}}=\sigma_{\mathrm{r}} \frac{\mathrm{Al}}{\tau_{\mathrm{m}} \mathrm{S}}
$$

$\tau_{\mathrm{m}}$ is the shear strength of Ti matrix. A is the cross-sectional areas of reinforcement, $S$ is Ti-reinforcement interfacial areas. $\mathrm{A}=\mathrm{wt}, \mathrm{S}=(\mathrm{w}+\mathrm{t}) \mathrm{l}, \mathrm{w}$ and $\mathrm{t}$ is the width and thickness of reinforcement.

2. The change of yield stress can be calculated using the Hall-Petch formula [22]:

$$
\sigma_{\mathrm{y}}=\sigma_{0}+\mathrm{kD}^{-0.5}
$$

where $\sigma_{\mathrm{y}}$ is the yield stress; $\sigma_{0}$ is the friction force to be overcome by dislocation motion; $\mathrm{k}$ is the constant related to the material, $\mathrm{k}=0.68 \mathrm{MPa} \cdot \mathrm{m}^{0.5}$; $\mathrm{D}$ is the grain size. The grains of TMCs are smaller than that of pure Ti. The yield stress increases with the average grain sizes decreasing. The yield stress of TMCs are bigger than that of Ti.

\subsubsection{Tribological Properties}

The Friction coefficient of Ti and TMCs under dry conditions is shown in Figure 8 and listed in Table 4. Figure 8 a shows friction coefficients of Ti and TMCs sintered at $1273 \mathrm{~K}$. 
There is a pre-grinding period at the beginning of friction, and the friction coefficient is rising sharply. The friction coefficient is stable in the period of 300-900 s. Such as Table 4, in Table 5, average friction coefficient of Ti1, TMC1, TMC2, TMC3 and TMC4 are 0.82, 0.70, $0.64,0.55$ and 0.67 , respectively. Compared with Ti1, the friction coefficient of the TMCs is reduced. It indicates that GO may play a lubrication role. The friction coefficient of TMCs sintered at $1373 \mathrm{~K}$ is shown in Figure 8b. During 300-900 s, average friction coefficients of Ti2, TMC5, TMC6, TMC7 and TMC8 are $0.70,0.68,0.50,0.72$ and 0.64 respectively. With the increase of GO content, the friction coefficient decreases to some extent, but when the $\mathrm{GO}$ content is $0.5 \mathrm{wt} . \%$ and $0.7 \mathrm{wt} . \%$, the friction coefficient increases. The reaction degree between $\mathrm{GO}$ and $\mathrm{Ti}$ is stronger with the increase of sintering temperature, and the retention of the GO structure is less, so the friction property decreases.

(a)

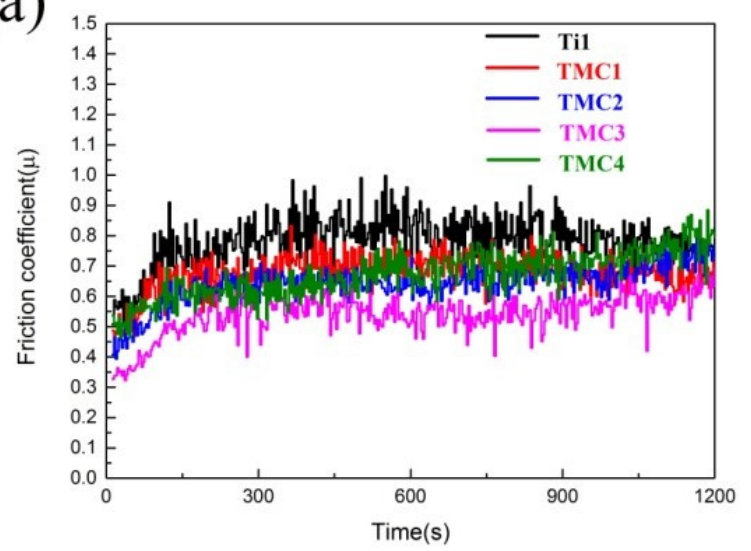

(b)

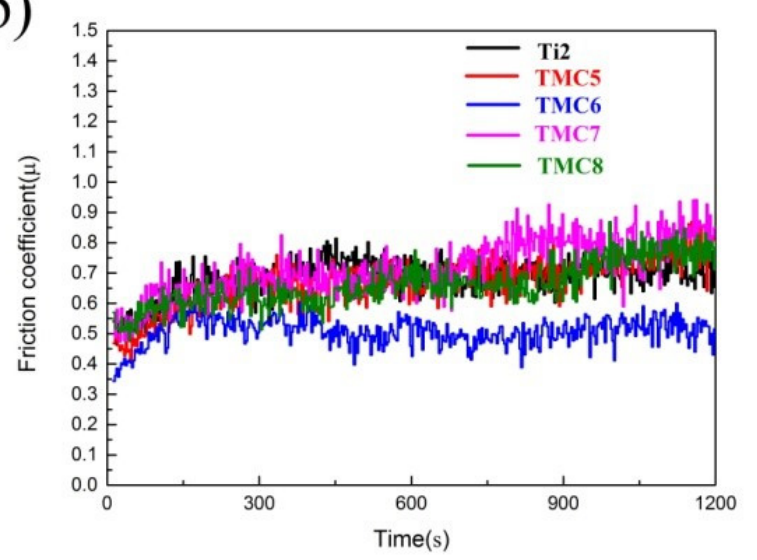

Figure 8. Friction coefficients of Ti and TMCs sintered at (a) $1273 \mathrm{~K}$ and (b) $1373 \mathrm{~K}$.

Table 5. Friction coefficient of Ti and TMCs.

\begin{tabular}{cccc}
\hline Materials & Friction Coefficient & Materials & Friction Coefficient \\
\hline Ti1 & $0.82 \pm 0.003$ & Ti2 & $0.70 \pm 0.002$ \\
TMC1 & $0.70 \pm 0.005$ & TMC5 & $0.68 \pm 0.004$ \\
TMC2 & $0.64 \pm 0.004$ & TMC6 & $0.50 \pm 0.003$ \\
TMC3 & $0.55 \pm 0.006$ & TMC7 & $0.72 \pm 0.007$ \\
TMC4 & $0.67 \pm 0.003$ & TMC8 & $0.64 \pm 0.005$ \\
\hline
\end{tabular}

Figure 9 shows the three-dimensional wear trace morphology and wear volume of TMCs under sliding dry friction. Compared with pure Ti, the wear degree of the TMCs is slower, and the wear resistance is consistent with the friction coefficient.

Figure 10 shows the friction surface morphology of TMC6. As is shown in Figure 10a, Obvious friction marks can be observed. Under the action of stress, granular debris is crushed and flattened, and then apparent abrasive wear marks are formed in Figure 10b. Figure 10d is an EDS analysis of the wear marks of the TMC6 in Figure 10c. It shows that there is $\mathrm{C}$ of GO is squeezed to the surface due to the friction force. Then, a film with lubrication is formed on the contact surface between the friction pair and the matrix, thus reducing the wear of the friction pair to the matrix. And, there are Fe elements only in friction pairs. Results show that material transfer of friction pair and surface element oxidation occurs in the friction and wear process. The wear mechanism is adhesive wear and oxidation wear. 

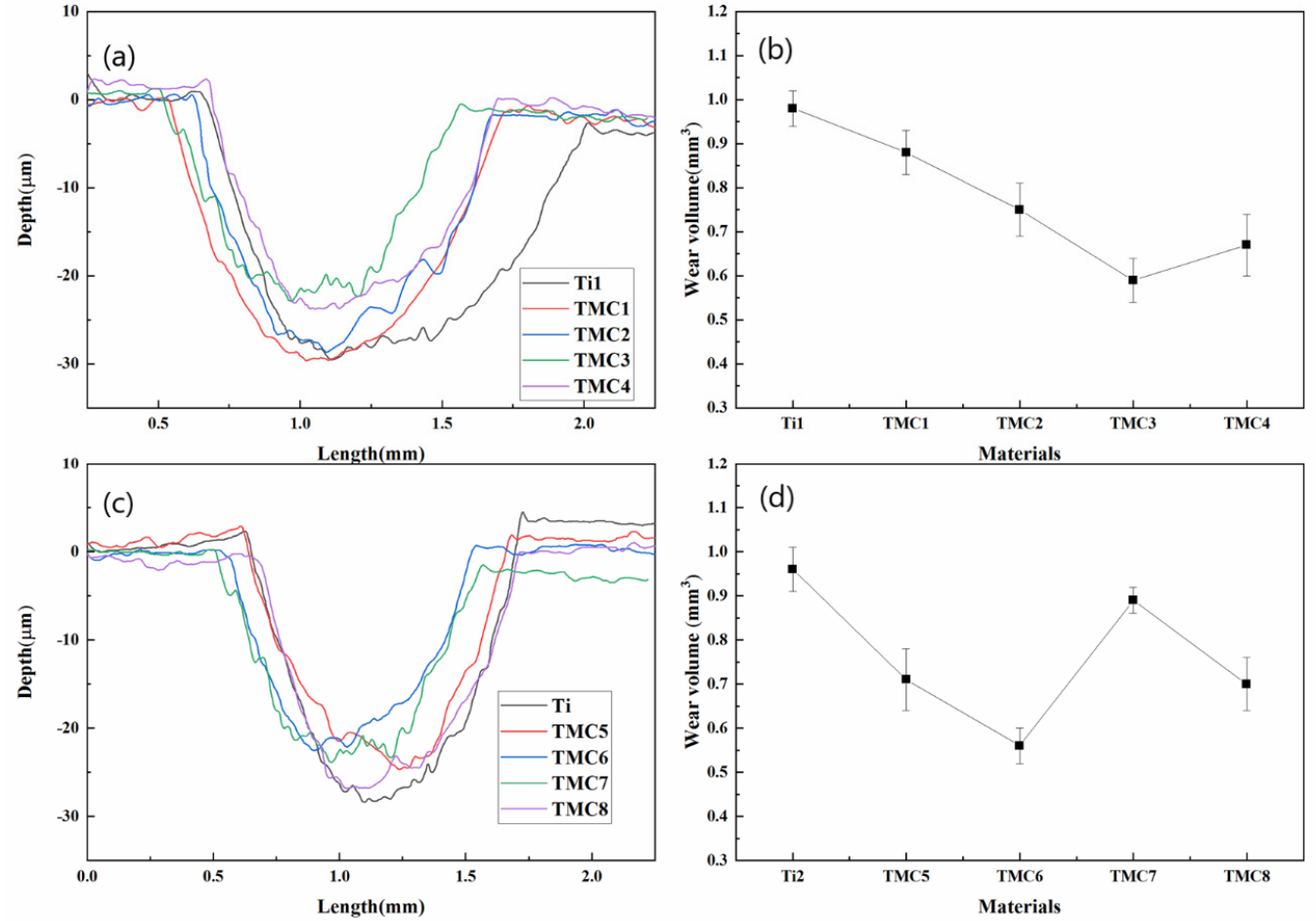

Figure 9. Depth of wear marks and wear volume of Ti and TMCs. (a) Depth of wear marks of Ti and TMCs sintered at $1273 \mathrm{~K}$. (b) Wear volume of Ti and TMCs sintered at $1273 \mathrm{~K}$. (c) Depth of wear marks of Ti and TMCs sintered at $1373 \mathrm{~K}$. (d) Wear volume of TMCs sintered at $1373 \mathrm{~K}$.
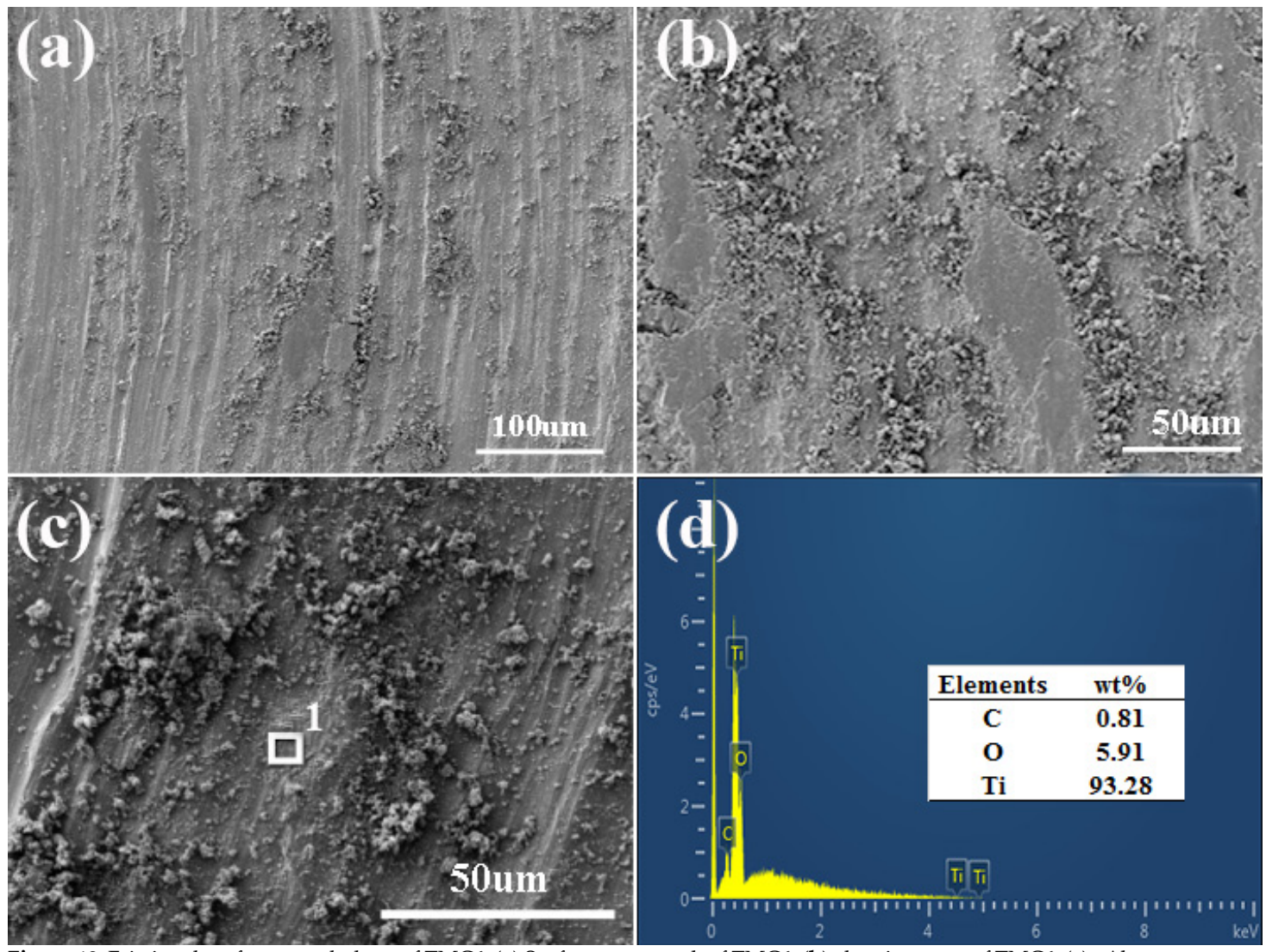

Figure 10. Frictional surface morphology of TMC6. (a) Surface wear mark of TMC6; (b) abrasive wear of TMC6; (c) a Abrasive particle of TMC6; (d) EDS of TMC6 in (c). 


\section{Conclusions}

$0.1-0.7 \mathrm{wt} . \%$ of GO / Ti composites were prepared by hot-pressed sintering at $1273 \mathrm{~K}$ and $1373 \mathrm{~K}$. The results demonstrated that this method is simple and highly efficient to fabricate GO/Ti composites with remarkably high mechanical properties, which will meet the industrial development of lightweight, high-strength materials. The results of the current investigation are as follows:

1. The microstructure of Ti and TMCs is equiaxed $\alpha$. The average grain size of TMCs decreases with GO increasing. GO and TiC exists in TMCs simultaneously.

2. The hardness of TMCs is higher than that of pure Ti. The hardness of TMCs with 0.7 wt. $\%$ GO sintered at $1373 \mathrm{~K}$ is the biggest, $320 \mathrm{HV}$, which is $43 \%$ higher than that of pure Ti. The yield strength of $0.5 \mathrm{wt} . \%$ GO sintered at $1373 \mathrm{~K}$ is $1324 \mathrm{MPa}, 77 \%$ more than pure Ti. The strengthening mechanism is that reinforcement bears the load from matrix and fine-grain strengthening.

3. Compared with pure Ti under the same condition, the friction coefficient of TMCs decreases. The friction coefficient of TMCs containing $0.5 \mathrm{wt} . \% \mathrm{GO}$ sintered at $1273 \mathrm{~K}$ and $0.3 \mathrm{wt.} \% \mathrm{GO}$ sintered at $1373 \mathrm{~K}$ is 0.55 and 0.5 , which are 0.27 and 0.2 lower than that of pure Ti. The wear mechanism is abrasive wear, adhesive wear and oxidation wear.

Author Contributions: Z.W., investigation, performing the experiment, writing-original draft preparation; S.H., investigation, part of writing-original draft preparation; J.L., conceptualization, review \& editing, supervision. D.Y., conceptualization, review \& editing. All authors have read and agreed to the published version of the manuscript.

Funding: This research received no external funding.

Institutional Review Board Statement: Not applicable.

Informed Consent Statement: Not applicable.

Data Availability Statement: The data supporting the finding of this study are available within the article.

Conflicts of Interest: The authors declare no conflict of interest.

\section{References}

1. Hua, K.; Wan, Q.; Zhang, Y.; Kou, H.; Li, J. Crystallography and microstructure of the deformation bands formed in a metastable $\beta$ titanium alloy during isothermal compression. Mater. Charact. 2021, 176, 111119. [CrossRef]

2. Lu, H.F.; Wang, Z.; Cai, J.; Xu, X.; Lu, J. Effects of laser shock peening on the hot corrosion behaviour of the selective laser melted Ti6Al4V titanium alloy. Corros. Sci. 2021, 188, 109558. [CrossRef]

3. Yang, D.; Liu, Y.L.; Xie, F.; Wu, M. Identification and Quantitative Analysis of the Isolated and Adhesive Beta Phases in Titanium Alloy Ti-6Al-4V. Mater. Trans. 2020, 61, 1220-1229. [CrossRef]

4. Fourest, T.; Bouda, P.; Fletcher, L.C.; Notta-Cuvier, D.; Markiewicz, E.; Pierron, F.; Langrand, B. Image-Based Inertial Impact Test

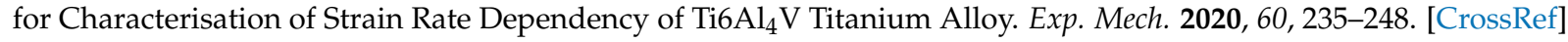

5. Bansal, P.; Singh, G.; Sidhu, H.S. Plasma-Sprayed HA/Sr Reinforced Coating for Improved Corrosion Resistance and Surface Properties of Ti13Nb13Zr Titanium Alloy for Biomedical Implants. J. Mater. Res. 2021, 36, 431-442. [CrossRef]

6. Wang, X.; Li, S.; Han, Y.; Huang, G.; Lu, W. Roles of reinforcements in twin nucleation and nano- $\alpha$ precipitation in the hybrid $\mathrm{TiB} / \mathrm{TiC}-$ reinforced titanium matrix composites during high-temperature fatigue. Scr. Mater. 2021, 196, 113758. [CrossRef]

7. Mcintyre, D.J.; Hirschman, R.K.; Puchades, I.; Landi, B.J. Enhanced copper-carbon nanotube hybrid conductors with titanium adhesion layer. J. Mater. Sci. 2020, 55, 6610-6622. [CrossRef]

8. Li, H.; Jia, D.; Yang, Z.; Zhou, Y. Achieving near equiaxed $\alpha$-Ti grains and significantly improved plasticity via heat treatment of TiB reinforced titanium matrix composite manufactured by selective laser melting. J. Alloys Compd. 2020, 836, 155344. [CrossRef]

9. Li, A.; Shi, L.; Zhang, W.; Zhou, S.Q.; Sun, Y.J.; Ma, S.; Liu, M.B.; Sun, Y. A simple way to fabricate Ti6Al4V matrix composites reinforced by graphene with exceptional mechanical properties. Mater. Lett. 2019, 257, 126750. [CrossRef]

10. $\mathrm{Hu}, \mathrm{C} . \mathrm{L}$.; Sun, R.L. Microstructure of $\mathrm{B}_{4} \mathrm{C} / \mathrm{TiC} / \mathrm{TiB}_{2}$ reinforced surface titanium matrix composite produced by laser cladding. IOP Conf. Ser. Mater. Sci. Eng. 2020, 770, 012003. [CrossRef]

11. Ying, W.; Peng, X.S. Graphene oxide nanoslit-confined AgBF4/ionic liquid for efficiently separating olefin from paraffin. Nanotechnology 2020, 31, 085703. [CrossRef] 
12. Yao, W.; Tang, L.L.; Nong, J.P.; Wang, J.; Yang, J.; Jiang, Y.D.; Shi, H.F.; Wei, X.Z. Electrically tunable graphene metamaterial with strong broadband absorption. Nanotechnology 2021, 32, 075703. [CrossRef] [PubMed]

13. Wang, F.Z.; Cai, X.X. Improvement of mechanical properties and thermal conductivity of carbon fiber laminated composites through depositing graphene nanoplatelets on fibers. J. Mater. Sci. 2019, 54, 3847-3862. [CrossRef]

14. Kumar, S.; Singh, K.K.; Ramkumar, J. Comparative study of the influence of graphene nanoplatelets filler on the mechanical and tribological behavior of glass fabric-reinforced epoxy composites. Polym. Compos. 2020, 41,5403-5417. [CrossRef]

15. Xavior, M.A.; Kumar, H.P. Processing and Characterization Techniques of Graphene Reinforced Metal Matrix Composites (GRMMC); A Review. Mater. Today Proc. 2017, 4, 3334-3341. [CrossRef]

16. Rashad, M.; Pan, F.S.; Asif, M.; Tang, A.T. Powder metallurgy of Mg-1\%Al-1\%Sn alloy reinforced with low content of graphene nanoplatelets (GNPs). J. Ind. Eng. Chem. 2014, 20, 4250-4255. [CrossRef]

17. Zhou, W.; Mikulova, P.; Fan, Y.C.; Kikuchi, K.; Nomura, N.; Kawasaki], A. Interfacial reaction induced efficient load transfer in few-layer graphene reinforced Al matrix composites for high-performance conductor. Compos. Part B 2019, 179, 107463. [CrossRef]

18. Han, X.Q.; Yang, L.Z.; Zhao, N.Q.; He, C.N. Copper-Coated Graphene Nanoplatelets-Reinforced Al-Si Alloy Matrix Composites Fabricated by Stir Casting Method. Acta Metall. Sin. 2020, 34, 111-124. [CrossRef]

19. Ali, S.; Ahmad, F.; Yusoff, P.S.M.M.; Muhamad, N.; Qnate, E.; Raza, M.R.; Malik, K. A review of graphene reinforced Cu matrix composites for thermal management of smart electronics. Compos. Part A 2021, 144, 106357. [CrossRef]

20. Shin, S.E.; Choi, H.J.; Shin, J.H.; Bae, D.H. Strengthening behavior of few-layered graphene/aluminum composites. Carbon 2015, 82, 143-151. [CrossRef]

21. Chen, F.Y.; Ying, J.M.; Wang, Y.F.; Du, S.Y.; Liu, Z.P.; Huang, Q. Effects of graphene content on the microstructure and properties of copper matrix composites. Carbon 2016, 96, 836-842. [CrossRef]

22. Liu, J.H.; Khan, U.; Coleman, J.; Fernandez, B.; Rodriguez, P.; Naher, S.; Brabazon, D. Graphene oxide and graphene nanosheet reinforced aluminium matrix composites: Powder synthesis and prepared composite characteristics. Mater. Des. 2016, 94, 87-94. [CrossRef]

23. Shuai, C.J.; Wang, B.; Yang, Y.W.; Peng, S.P.; Gao, C.D. 3D honeycomb nanostructure-encapsulated magnesium alloys with superior corrosion resistance and mechanical properties. Compos. Part B 2019, 162, 611-620. [CrossRef]

24. Mu, X.N.; Zhang, H.M.; Cai, H.N.; Fan, Q.B.; Zhang, Z.H.; Wu, Y.; Fu, Z.J.; Yu, D.H. Microstructure evolution and superior tensile properties of low content graphene nanoplatelets reinforced pure Ti matrix composites. Mater. Sci. Eng. A 2017, 687, 164-174. [CrossRef]

25. Cao, Z.; Li, J.L.; Zhang, H.P.; Li, W.B.; Wang, X.D. Mechanical and tribological properties of graphene nanoplatelets-reinforced titanium composites fabricated by powder. J. Iron Steel Res. Int. 2020, 21, 1357-1362. [CrossRef]

26. Dong, L.L.; Xiao, B.; Jin, L.H.; Lu, J.W.; Liu, Y.; Fu, Y.Q.; Zhao, Y.Q.; Wu, G.H.; Zhang, Y.S. Mechanisms of simultaneously enhanced strength and ductility of titanium matrix composites reinforced with nanosheets of graphene oxides. Ceram. Int. 2019, 45, 19370-19379. [CrossRef]

27. Cao, H.C.; Liang, Y.L. The microstructures and mechanical properties of graphene-reinforced titanium matrix composites. J. Alloys Compd. 2020, 812, 152057. [CrossRef]

28. Liu, J.; Wu, M.X.; Yang, Y.; Yang, G.; Yan, H.X.; Jiang, K.L. Preparation and mechanical performance of graphene platelet reinforced titanium nanocomposites for high temperature applications. J. Alloys Compd. 2018, 765, 1111-1118. [CrossRef]

29. Dong, L.L.; Xiao, B.; Liu, Y.; Li, Y.L.; Fu, Y.Q.; Zhao, Y.Q.; Zhang, Y.S. Sintering effect on microstructural evolution and mechanical properties of spark plasma sintered Ti matrix composites reinforced by reduced graphene oxides. Ceram. Int. 2018, 44, 17835-17844. [CrossRef]

30. Chen, H.; Mi, G.B.; Li, P.J.; Huang, X.; Cao, C.X. Microstructure and Tensile Properties of Graphene-Oxide-Reinforced HighTemperature Titanium-Alloy-Matrix Composites. Materials 2020, 13, 3358. [CrossRef]

31. Haghighi, M.; Shaeri, M.H.; Sedghi, A.; Djavanroodi, F. Effect of Graphene Nanosheets Content on Microstructure and Mechanical Properties of Titanium Matrix Composite Produced by Cold Pressing and Sintering. Nanomaterials 2018, 8, 1024. [CrossRef] [PubMed]

32. Liu, J.Q.; Hu, N.; Liu, X.Y.; Liu, Y.L.; Lv, X.W.; Wei, L.X.; Zheng, S.T. Microstructure and Mechanical Properties of Graphene OxideReinforced Titanium Matrix Composites Synthesized by Hot-Pressed Sintering. Nanoscale Res. Lett. 2019, 14, 114. [CrossRef] [PubMed]

33. $\mathrm{Mu}$, X.N.; Cai, H.N.; Zhang, H.M.; Fan, Q.B.; Wang, F.C.; Cheng, X.W.; Zhang, Z.H.; Li, J.B.; Jiao, X.L.; Ge, Y.X.; et al. Size effect of flake Ti powders on the mechanical properties in graphene nanoflakes/Ti fabricated by flake powder metallurgy. Compos. Part $A$ 2019, 123, 86-96. [CrossRef] 